\title{
Expression of intrahepatic hepatitis D viral antigen in chronic hepatitis $\mathrm{D}$ virus infection
}

\author{
J Y N Lau, L J Hansen, V G Bain, K Chaggar, H M Smith, B C Portman, D Vergani, \\ $\mathrm{G} J$ M Alexander, $R$ Williams
}

\begin{abstract}
To elucidate the biological importance of intrahepatic hepatitis $D$ virus antigen, its expression was correlated with biochemical and histological inflammatory activity in 98 biopsy specimens from 68 patients seropositive for total antibody to the virus. Seventy five specimens were positive for intrahepatic nuclear antigen for HDV antigen accompanied by cytoplasmic HDV antigen in only one biopsy specimen. This group had significantly higher serum transaminase activities and inflammatory activity than the remaining cases that were negative for HDV antigen. Among the group positive for HDV antigen, there was no correlation between the proportion of hepatocytes containing HDV antigen and either serum transaminase activity or histological inflammatory indices.
\end{abstract}

In $22 \mathrm{HDV}$ antigen positive patients who had follow up biopsy specimens taken at a median of two years, the proportion with cirrhosis increased from $36 \%$ to $73 \%$. Serum transaminase activities remained the same during this period, but the proportion of HDV antigen positive cells dropped. Follow up of 51 patients showed that 21 died or underwent liver transplantation within three years.

The absence of an association between intrahepatic HDV antigen expression and progression of histological liver damage does not support the view that HDV is directly cytopathic to hepatocytes. Immune mediated mechanisms may have a role in the pathogenesis of chronic liver disease related to HDV infection.

Institute of Liver Studies, King's College Hospital School of Medicine and Dentistry, Denmark Hill, London SE5 9PJ

J Y N Lau

L J Hansen

V G Bain

K Chaggar

H M Smith

B C Portman

G J M Alexander

$\mathrm{R}$ Williams

Department of Immunology, King's College Hospital D Vergani

Correspondence to: Dr Roger Williams Accepted for publication 12 February 1991

The presence of chronic hepatitis $\mathrm{D}$ virus (HDV) superinfection is associated with more severe and progressive disease in hepatitis B virus (HBV) carriers. ${ }^{1}$ It is still uncertain, however, whether HDV is cytopathic or whether liver damage is immune mediated. Measured by serum HDV RNA and in situ HDV RNA hybridisation, HDV antigen is an excellent marker for active HDV replication..$^{2-4}$ More recently, a significant positive correlation was observed between the number of HDV antigen positive cells and the extent of portal inflammation. ${ }^{5}$ To elucidate further the biological importance of hepatocyte HDV fection, immunohistochemical staining was used to assess the expression of HDV antigen in liver tissue for correlation with clinical, biochemical, and histological evidence of activity and the rapidity of the clinical course.

\section{Methods}

All patients seen at the Institute of Liver Studies of King's College Hospital between 1983 and 1989 for evaluation of chronic liver diseases had serum hepatitis B virus surface antigen (HBsAg) determined when a viral aetiology was suspected. Total antibody to HDV was sought routinely in all serum samples positive for $\mathrm{HBsAg}$ and antibody to human immunodeficiency virus (HIV) was tested in all high risk patients. Among the $\mathbf{8 0}$ patients positive for total antibody to $\mathrm{HDV}$, 68 patients with 98 liver biopsy/hepatectomy specimens were included. Twelve patients were excluded; in 10 (all resident abroad) a liver biopsy had been carried out shortly before referral, or severe coagulopathy had precluded this investigation; another two British patients were excluded because they were positive for markers of HIV infection. The clinical, biochemical, and histological variables of these patients are summarised in table 1. Only liver biochemistry assessed within two days of the liver biopsy are recorded here, and used for subsequent correlation studies (87 of the 98 biopsy specimens).

Serum was tested for $\mathrm{HBsAg}, \mathrm{HBV}$ e antigen $(\mathrm{HBeAg})$, anti-HBe and total antibody to HDV by radioimmunoassay (Abbott Diagnostics, Maidenhead, England). Enzyme immunoassays were used to detect IgM anti-HDV (Noctech, Dublin, Eire) and antibody to HIV (Abbott Diagnostics). Serum HBV DNA was

Table 1 Clinical, biochemical, and histological data of patients studied antigen in pathogenesis of chronic HDV in-
Number of patients Male:female

Median age (range)

Non-British nationals

Positive family history

ntravenous drug abuse

Serum biochemistry:

SGOT (IU/1)

Bilirubin $(\mu \mathrm{mol} / \mathrm{l})$

Albumin $(\mathrm{g} / \mathrm{l})$

Alkaline phosphatase (IU/1)

Liver histology (number of biopsy specimens):

Non-specific reactive change

Chronic persistent hepatitis

Chronic active hepatitis

Active cirrhosis (with hepatocellular

carcinoma)

\begin{tabular}{|c|c|}
\hline $\begin{array}{l}68 \\
60: 8 \\
37 \\
41 \\
16 \\
26\end{array}$ & $(21-71)$ \\
\hline $\begin{array}{c}\text { Mear } \\
114 \\
53 \\
33 \\
114\end{array}$ & $\begin{array}{c}n \text { (range) } \\
(14-440) \\
(6-411) \\
(20-49) \\
(46-569)\end{array}$ \\
\hline $\begin{array}{r}1 \\
11 \\
23\end{array}$ & \\
\hline 63 & (5) \\
\hline
\end{tabular}


assayed using a quantitative dot-blot technique, as previously described. ${ }^{6}$

Histological diagnosis was established by internationally accepted criteria ${ }^{7}$ and activity was independently assessed by one of us (BCP). Three histological factors were assessed: lobular inflammation $(1+=$ mild, $2+=$ moderate, $3+=$ severe), portal tract inflammation $(1+=$ sparse, $2+=$ moderate, $3+=$ dense), and piece-meal necrosis $(1+=$ patchy, $2+=\approx 50 \%$ of the limiting plates affected, $3+=$ most limiting plates affected). When these were added together, a total histological activity index was derived $(0-9+)$. Fibrosis was assessed independently because it is more an indicator of previous inflammatory damage rather than current disease activity. It was graded from 0 to $4+(1+=$ portal, $2+=$ porto-septal, $3+=$ bridging, $4+=$ cirrhosis).

DETECTION OF HDV ANTIGEN IN LIVER TISSUE Two batches of polyclonal anti-HDV antigen were used: the first batch was fluorescein isothiocyanate labelled antibody; later peroxidase labelled antibody was purchased from Sorin Biomedica (Saluggia, Italy). These antibodies showed similar sensitivity in six paired liver biopsy specimens.

Sections ( $5 \mu \mathrm{m}$ thick) were prepared according to previous recommendations. ${ }^{8}$ In particular, formalin fixation did not exceed 24 hours, sections were heated $\left(56^{\circ} \mathrm{C}\right.$ for $10 \mathrm{~min}$ utes) before dewaxing in xylene for only 20 minutes, then rehydrated in graded alcohol solutions. For peroxidase labelled antibodies, endogenous peroxidase activity was inhibited by standard methanol peroxide. The sections were then digested with $0.05 \%$ pronase type XXVII (Sigma, Dorset) in phosphate buffered saline (PBS) for 30 minutes at room temperature. After washing in PBS the sections were covered with fluorescent or peroxidase labelled polyclonal antibody at room temperature for 30 minutes. For peroxidase labelled antibody, the substrate was diaminobenzidine $\left(0.5 \mathrm{mg} / \mathrm{ml}\right.$ in PBS plus $\left.0.01 \% \mathrm{H}_{2} \mathrm{O}_{2}\right)$ and sections were then counterstained with haematoxylin and mounted in DPX.

To account for the possibility that membranous/cytoplasmic HDV antigen might be blocked by the patients' own antibody, three paraffin wax sections and two cryostat sections were washed with $0.05 \mathrm{M}$ acidic glycine- $\mathrm{HCl}$ (pH 3.0) for five minutes to release any antibody bound to HDV antigen followed by three washes with PBS before immunohistochemical staining. The staining was essentially the same, indicating that absence of cytoplasmic HDV antigen was not due to blockage by endogenous antibody.

The expression of HDV antigen was scored independently by two of us (JYNL, BCP) on a $0-4+$ scale, corresponding to positivity in $0 \%$, $1-5 \%, 5-30 \%, 30-60 \%$, and $>60 \%$ of hepatocytes examined, respectively.

Results were analysed using Fisher's exact test, Student's $t$ test, Wilcoxon's rank sum test and the Spearman rank correlation test where appropriate.

\section{Results}

The expression of $\mathrm{HDV}$ antigen in the liver specimens: $0: 23(23.5 \%) ; 1+: 36(36.7 \%) ; 2+$ : $30(30.6 \%) ; 3+: 9(9.2 \%)$ and $4+: 0$. Of the positive biopsy specimens, all except one had nuclear HDV antigen only, the exception being positive for both nuclear and cytoplasmic HDV antigen. There was no difference in intrahepatic $\mathrm{HDV}$ antigen expression between the male and female patients.

\section{CORRELATION OF INTRAHEPATIC HDAg} EXPRESSION AND ACTIVITY OF LIVER DISEASE Intrahepatic $\mathrm{HDV}$ antigen positive biopsy specimens were associated with significantly higher serum transaminase (SGOT) activity, positive IgM anti-HDV, and more advanced liver disease (table 2). Surprisingly, there was no correlation between serum transaminase activity and the extent of intrahepatic HDV antigen expression (fig 1).

Intrahepatic HDV antigen expression was also associated with a higher histological activity index (fig 2). Biopsy specimens positive for intrahepatic HDV antigen had significantly higher histological inflammatory activity scores compared with those without (HDV antigen positive $v \mathrm{HDV}$ antigen negative $(\mathrm{p}<0.001)$ ) but there was again no correlation between the histological activity scores and the extent of intrahepatic HDV antigen expression. When HDV antigen expression was correlated with individual factors that comprised this histological activity index - that is, portal inflamma-

Table 2 Differences between intrahepatic HDV antigen positive and negative biopsy specimens in relation to SGOT, IgM anti-HDV positivity, and liver histology

\begin{tabular}{|c|c|c|c|}
\hline \multirow[b]{2}{*}{ · } & \multicolumn{2}{|l|}{ Intrahepatic distribution } & \multirow[b]{2}{*}{ p Value } \\
\hline & HDV antigen positive & $H D V$ antigen negative & \\
\hline $\begin{array}{l}\text { SGOT: } \\
\text { Number measured } \\
\text { Number with normal SGOT }(\%)\end{array}$ & $\begin{array}{l}71 \\
11 \quad(15 \cdot 5 \%)\end{array}$ & $\begin{array}{r}16 \\
8 \quad(50 \%)\end{array}$ & $p=0.011$ \\
\hline $\begin{array}{l}\operatorname{IgM} \text { anti-HDV: } \\
\text { Number assessed } \\
\text { Number positive for IgM anti-HDV }\end{array}$ & $\begin{array}{l}68 \\
64\end{array}$ & $\begin{array}{l}22 \\
14\end{array}$ & $p=0.0021$ \\
\hline $\begin{array}{l}\text { Histology: } \\
\text { Non-specific reactive changes } \\
\text { Chronic persistent hepatitis } \\
\text { Chronic active hepatitis } \\
\text { Active cirrhosis }\end{array}$ & $\begin{array}{r}0 \\
5 \\
20 \\
50\end{array}$ & $\left.\begin{array}{r}1 \\
6 \\
3 \\
13\end{array}\right\}$ & $p=0.0012$ \\
\hline
\end{tabular}


Figure 1 Relation between intrahepatic expression of $H D V A g$ and serum aspartate transaminase activity. ( $\square$ those with positive intrahepatic $\mathrm{HBc} \mathrm{Ag}$, all nuclear (in distribution).

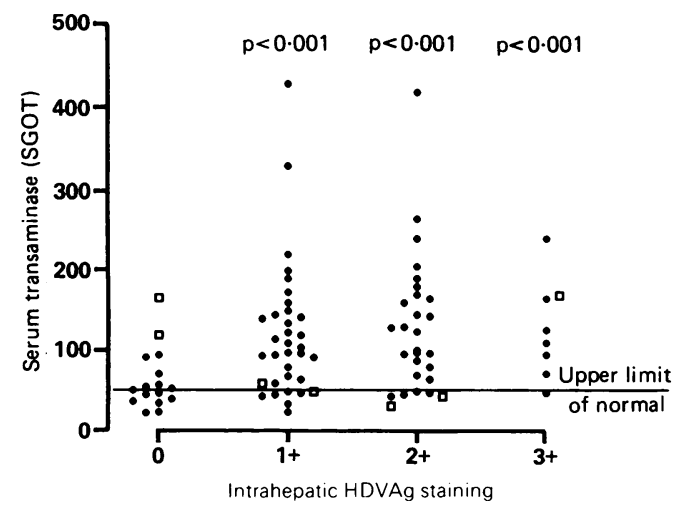

tion, lobular inflammation, piece-meal necrosis -all three factors were significantly higher in those biopsy specimens positive for HDV antigen (table 3$)$. Seventy nine $(81 \%)$ of all the biopsy specimens had either bridging fibrosis or cirrhosis, but there was no correlation between the extent of fibrosis and intrahepatic HDV antigen expression.

In 25 patients (three with intrahepatic HDV antigen positivity) with follow up biopsies performed at a median of two years (range one to five years), cellular liver histology had either remained static or deteriorated (fig $3 \mathrm{~A}$ ). The three patients negative for intrahepatic HDV antigen showed no changes in the follow up liver biopsy specimens. Among those positive for intrahepatic HDV antigen, there was no significant change in the histological inflammatory activity scores and serum transaminase values. Expression of intrahepatic HDV antigen, however, dropped in nine follow up biopsy specimens while the liver histology was either static or deteriorating (fig 3B). In the two patients in whom an increase in intrahepatic HDV antigen positive cells was recorded in the second liver biopsy specimen, a third specimen taken at a median of two years later showed a drop in the number of HDV antigen positive cells.

\section{CORRELATION BETWEEN INTRAHEPATIC HDV} ANTIGEN EXPRESSION AND CLINICAL OUTCOME Follow up records were available in 51 patients; the remaining 17 were not British nationals. Twenty one $(41.2 \%)$ of these patients had died or had undergone liver transplantation with a median of one year (range 0 to four years). Most of the remaining patients who had a repeat liver biopsy performed showed a deterioration in liver histology. A higher proportion of patients with either absent or $1+$ intrahepatic HDV

Table 3 Significance of difference between those with intrahepatic HDV antigen expression and those without, in terms of total and individual activity index of liver inflammation

\begin{tabular}{llll}
\hline & \multicolumn{2}{l}{ Intrahepatic HDVAg expression } \\
\cline { 2 - 4 } & $1+(n=36)$ & $2+(n=30)$ & $3+(n=9)$ \\
\hline Total histological activity index & $\mathrm{p}<0.001$ & $\mathrm{p}<0.001$ & $\mathrm{p}<0.001$ \\
Portal inflammation & $\mathrm{p}<0.001$ & $\mathrm{p}<0.001$ & $\mathrm{p}<0.001$ \\
Lobular inflammation & $\mathrm{p}<0.001$ & $\mathrm{p}<0.001$ & $\mathrm{p}=0.008$ \\
Piece-meal necrosis & $\mathrm{p}=0.037$ & $\mathrm{p}<0.001$ & $\mathrm{p}<0.002$ \\
\hline
\end{tabular}

There was no difference between the HDV antigen positive groups in any of the histologica activity indices.

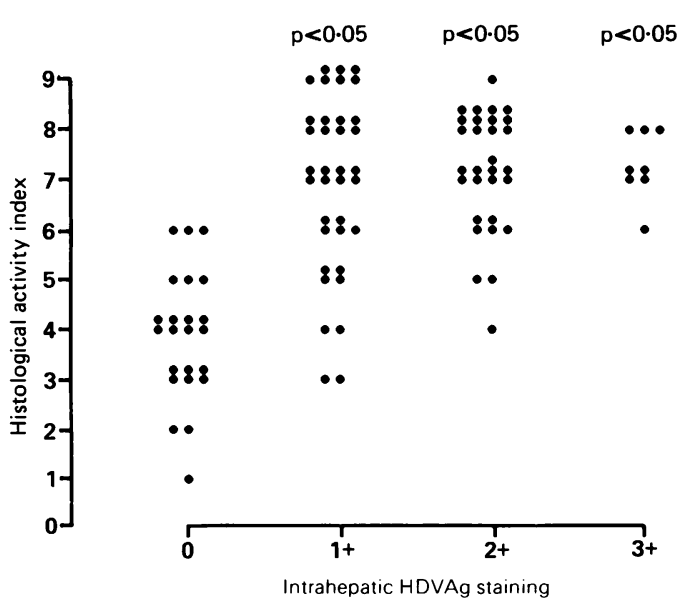

Figure 2 Relation between intrahepatic expression of $H D V A g$ and total histological activity index.

antigen had either died or undergone liver transplantation compared with those with $2+$ and $3+$ positivity. The four patients with $3+$ intrahepatic HDV antigen expression were still alive (two to four years), and in three of them a repeat liver biopsy specimen (median three years) showed a drop in the number of HDV antigen cells (fig 3B).

\section{RELATION BETWEEN INTRAHEPATIC HDV ANTIGEN AND HBV MARKERS}

Serum HBeAg and HBV DNA were found in eight and six patients, respectively, when they first presented. The HBV replication markers were not correlated with intrahepatic HDV antigen expression. Seven patients seropositive for $\mathrm{HBeAg}$ attended follow up; six lost $\mathrm{HBeAg}$ and five seroconverted to anti-HBe in a median of two years (range one to four years). All five patients with positive serum HBV DNA who attended follow up lost HBV DNA within three years. A repeat liver biopsy specimen taken in five showed deteriorated liver histology despite loss of HBV replication markers.

\section{Discussion}

Most of the patients with chronic HDV infection in this study had active liver disease on presentation, reflected by the high serum transaminase activity and numbers of inflammatory cells. The high proportion of patients with histological evidence of active cirrhosis on presentation and the five year mortality of around $40 \%$ were striking. Although this may in part be related to the fact that our unit is a referral centre, the high histological inflammatory activity index in most patients and the doubling of the proportion of cirrhosis in a median of two years in those HDV antigen positive patients with follow up biopsy specimens confirms the rapidly progressive nature of the disease.

The presence of intrahepatic HDV antigen is associated with active liver inflammatory activity, reflected by an increase in the serum transaminase activity and the histological activity scores. In addition to the association between intrahepatic HDV antigen expression and portal inflammation reported previously, ${ }^{4}$ 
Figure 3 Changes in liver histology and intrahepatic HDV Ag expression in those with follow up biopsy specimens taken. ( $A$ ) Liver histology; (B) expression of intrahepatic HDVAg. (1) and those with positive intrahepatic HDVAg on presentation, $\Delta$ and those with no intrahepatic HDV Ag present in the first liver biopsy specimen).

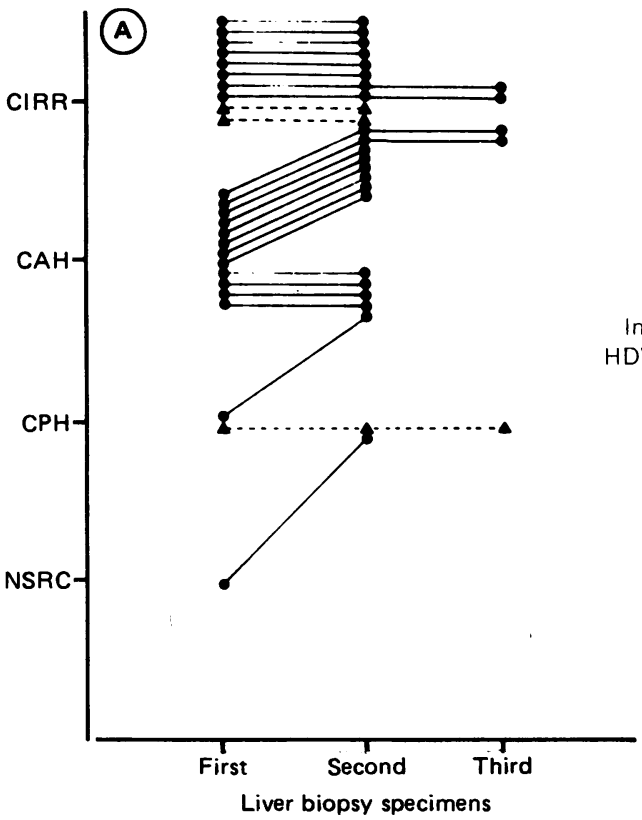

we have also shown that lobular inflammation and piece-meal necrosis were associated with HDV antigen expression. There was no correlation, however, between the extent of its expression and the activity of liver disease. This is unlikely to have been due to sampling error as the number in each group was not small. Furthermore, serum transaminase, which was significantly increased in those patients with intrahepatic HDV antigen expression, was not correlated with the extent of intrahepatic HDV antigen expression.

Intrahepatic HDV antigen is an excellent marker for active $\mathrm{HDV}$ replication. ${ }^{34}$ The polymerase chain reaction used to detect serum HDV RNA, is a better marker but it is not generally available. ${ }^{9}$ If HDV was cytopathic, then the extent of active HDV replication in the liver should be associated with active liver inflammation and hepatocyte damage. Such a pattern was not observed in our study. This casts doubt on the view that the rapid progression of the chronic liver disease is directly related to the cytopathic effects of the HDV virus. These data are supported by recent observations that in chronic HDV infection hepatocytes that show cytopathic changes usually do not contain HDV RNA or HDV antigen. ${ }^{41011}$ It is still possible that once the cytopathic changes develop the cells no longer produce the virus. Nevertheless, the consistent absence of HDV antigen in hepatocytes showing various stages of cytopathic changes in the three studies referred to above suggest that this is probably not the main factor in the pathogenesis of chronic liver disease. Recently, Davis et $a l$ also showed that the recurrence of HDV alone after liver transplantation was not associated with active liver disease. ${ }^{12}$

Recent studies have suggested that host immune factors, in particular $\mathrm{T}$ cell mediated immunity, might have an important role in the pathogenesis of liver cell damage in chronic HDV associated chronic liver disease. ${ }^{513}$ The degree of lymphocytic infiltration in the liver, together with the absence of a correlation between the extent of intrahepatic HDV anti-

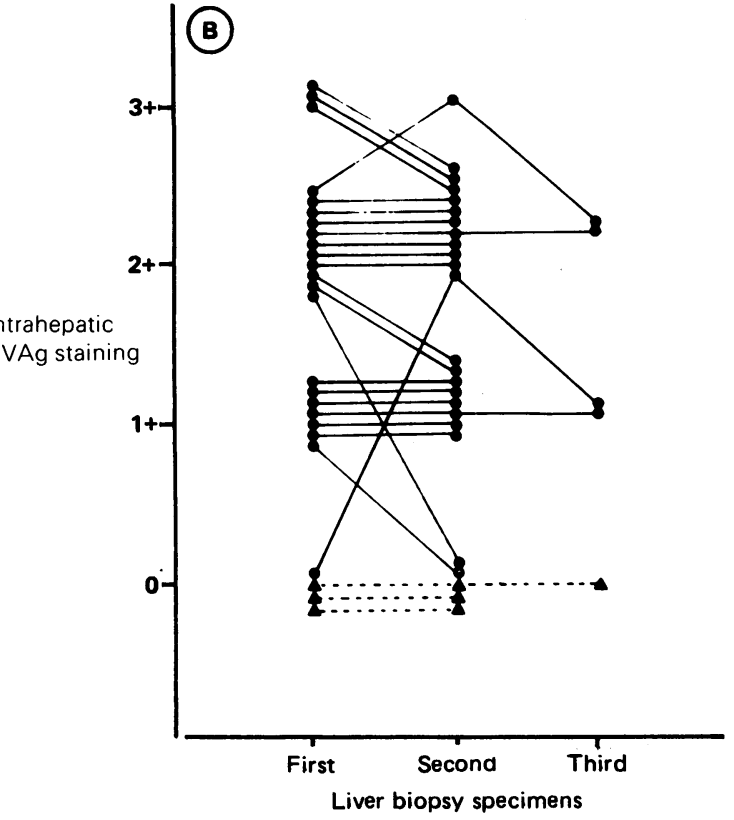

gen expression and liver inflammatory activities all agree with this hypothesis. This is also supported by the observation that a deterioration in liver histology in follow up biopsy specimens was associated with a decrease in intrahepatic HDV antigen expression, a pattern similar to that observed in chronic HBV infection, which is well known to induce liver damage through immune mediated mechanisms.

The nature of the target viral antigen in chronic HDV infection remains unresolved. Previous studies using immune electron microscopy in a small series showed that most patients had only nuclear HDV antigen. ${ }^{11}$ The possibility that treatment with pronase may destroy or remove the cytoplasmic HDV antigen is unlikely because cytoplasmic HDV antigen was shown consistently in most patients in whom HDV recurred after transplantation using the same immunohistochemical techniques (Davis et al, personal communication). There are several possible alternatives. Firstly, the HDV antigen may have been processed in the hepatocyte cytoplasm so that only $T$ cell epitopes are presented, rendering it a target for $T$ cells but undetectable by immunohistochemical methods which detect only B cell epitopes. Secondly, HDV may mediate liver cell damage through modulation of HBV antigen expression. As reported by others and also in this study, HBV replication and intrahepatic $\mathrm{HBcAg}$ expression were suppressed with HDV replication, making nucleocapsid antigens unlikely targets. ${ }^{14}$ Finally, chronic HDV infection is associated with autoantibodies and it is therefore possible that active HDV replication may induce the formation of a neoantigen, which in turn may be the target for the T cells. ${ }^{1}$

Our observation with respect to the suppression of HBV replication by HDV superinfection agrees with previous observations. ${ }^{14-16}$ It is interesting to note that most patients lost their HBV replication markers within three years, a timing which suggests a suppressive effect of HDV on HBV replication. 
We thank Dr Mario Rizzetto (Turin, Italy) for his kind gift of FITC conjugated antibody to HDV antigen. The technical assistance of $P$ Aldis and A Rayner is much appreciated. J Y N Lau is a Croucher Foundation Fellow. This paper was presented in part at the British Society of Gastroenterology Autumn in part at the British Society
Meeting 1990 in Southampton.

1 Rizzetto M, Verme G. Delta hepatitis. J Hepatol 1985;1 $187-93$

2 Smedile A, Rizzetto M, Denniston K, et al. Type D hepatitis: The clinical significance of hepatitis $D$ virus RNA in serum as detected by a hybridisation-based assay. Hepatology 1986;6:1297-302.

3 Govindarajan S, Gupta S, Valinluck B, Redeker AG. Correlation of IgM anti-hepatitis D virus (HDV) to HDV
RNA in sera of chronic HDV. Hepatology 1989;10:34-5. RNA in sera of chronic HDV. Hepatology 1989;10:34-5.
Negro F, Bonino F, Di Bisceglie A, Hoofnagle JH, Gerin JL Negro F, Bonino F, Di Bisceglie A, Hoofnagle JH, Gerin JL.
Intrahepatic markers of hepatitis delta virus infection A study by in-situ hybridisation. Hepatology 1989;10: 916-20

5 Negro F, Baldi M, Bonino F, et al. Chronic HDV (hepatitis delta virus) hepatitis: intrahepatic expression of delt antigen, histologic activity and outcome of liver disease. $J$ Hepatol 1988;6:8-14.

6 Fagan EA, Guanar P, Perera SDK, et al. Quantitation of hepatitis $B$ virus DNA in serum using the spot hybridisation technique and scintillation counting. JVirol Methods tion technique and
7 International Group. Acute and chronic hepatitis revisited. Lancet 1977;ii:914-9.

8 Trevisan A, Gudat F, Busachi C, Stocklin E, Bianchi L. An improved method for $\mathrm{HBcAg}$ demonstration in paraffinembedded liver tissue. Liver 1982;2:331-9.

9 Madejon A, Castillo I, Bartalome J, et al. Detection of HDV RNA by RCP in serum of patients with chronic HDV infection. J Hepatol 1990;11:381-4.

10 Verme G, Amoroso P, Lettieri G, et al. A histologic study of hepatitis delta virus liver disease. Hepatology 1986;6: 1303-7.

11 Kojima T, Callea F, Desmyter J, Desmet VJ. Immune electron microscopy of hepatitis $\delta$-antigen in hepatocytes. Lab Invest 1986;55:217-25.

12 Davis SE, Portmann B, O'Grady JG, Alexander GJM Williams R. Absence of liver damage with hepatitis D virus infection alone following liver transplantation. virus infection alone

13 Chu CM, Liaw YF. Studies on the composition of the mononuclear cell infiltrates in liver from patients with chronic active delta hepatitis. Hepatology 1989;10:911-5.

14 Krogsgaard K, Kryger P, Aldershvile J, et al. $\delta$-infection and suppression of hepatitis B virus replication in chronic HBsAg carriers. Hepatology 1987;7:42-5.

15 Rizzetto M, Canese MG, Gerlin JL, et al. Transmission of the hepatitis $B$ virus associated delta antigen to chimpanzees. J Infect Dis 1980;141:590-602.

16 Krogsgaard K, Aldershvile J, Kryger P, et al. Hepatitis B virus DNA, $\mathrm{HBeAg}$ and delta infection during the course from acute to chronic hepatitis B virus infection. Hepatology 1985;5:778-82. 